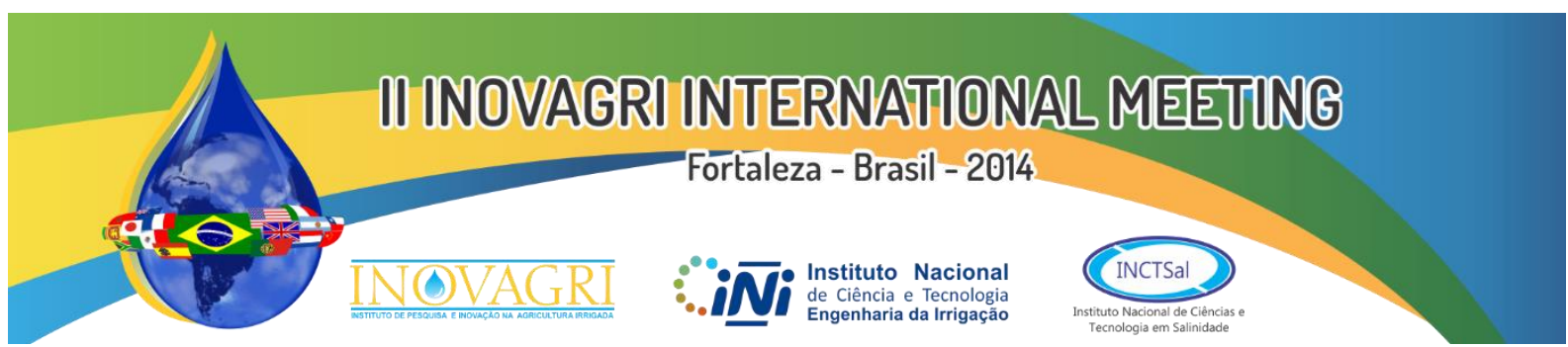

http://dx.doi.org/10.12702/ii.inovagri.2014-a681

\title{
DINÂMICA DO POTÁSSIO NO SOLO CULTIVADO COM VIDEIRA DE VINHO FERTIRRIGADA: $1^{\circ}$ CICLO DE PRODUÇÃO
}

\author{
D. J. Silva ${ }^{1}$; A. O. Silva ${ }^{2}$; L. H. Bassoi ${ }^{1}$; D. R. M. Souza ${ }^{3}$ L L. M. Santos ${ }^{3}$;B. D. R. Barbosa ${ }^{3}$
}

RESUMO: A fruticultura irrigada no Vale do Submédio São Francisco é uma das principais fontes de renda e emprego na região, com destaque para a prática da vitivinicultura. Com o objetivo de determinar a disponibilidade de potássio na solução do solo, em função de cinco doses $(0,20,40,80$ e $160 \mathrm{~kg} \mathrm{ha}^{-1}$ ), um experimento foi instalado na Embrapa Semiárido, em Petrolina-PE, com videiras (Vitis vinifera L.) 'Syrah' enxertadas sobre o porta-enxerto 'Paulsen' 1103 e cultivadas no espaçamento $3 \times 1 \mathrm{~m}$. O sistema de irrigação utilizado foi o gotejamento, com um emissor de $2 \mathrm{~L} \mathrm{~h}^{-1}$ por planta. Foram avaliadas durante o período de 111 dias as concentrações de potássio $\left(\mathrm{K} \mathrm{mg} \mathrm{L}^{-1}\right)$, nitrato $\left(\mathrm{N}-\mathrm{NO}_{3}, \mathrm{mg} \mathrm{L}^{-1}\right), \mathrm{pH}$ e condutividade elétrica $\left(\mathrm{CE}, \mathrm{dS} \mathrm{m}{ }^{-1}\right)$ na solução do solo. Para extração da solução do solo, foram instalados 30 extratores de cápsulas porosas nas profundidades do solo de 0,4 $\mathrm{m}$ e $0,6 \mathrm{~m}$. Os dados foram submetidos à análise de variância e de regressão linear e polinomial. As médias foram comparadas entre as profundidades estudadas pelo teste $\mathrm{F}$ a $5 \%$ de probabilidade. As dosagens estudadas apresentaram efeito significativo para a concentração de potássio, apresentando comportamento linear com acréscimo de 0,45 e $0,33 \mathrm{mg} \mathrm{L}^{-1}$ (nas profundidades de 0,4 e 0,6 m, respectivamente) na solução do solo para cada aumento unitário $\left(\mathrm{kg} \mathrm{ha}^{-1}\right)$ de fertilizante potássico no solo. $\mathrm{O}$ aumento das dosagens de fertilizantes potássicos aumentou a concentração de $\mathrm{K}$ na solução do solo, porém não foram observadas perdas por lixiviação deste nutriente.

PALAVRAS-CHAVE: Vitis vinifera L., fertirrigação, solução do solo

\section{DYNAMICS OF POTASSIUM IN THE SOIL CULTIVATED WITH FERTIRRIGATED VINE: $1^{\text {st }}$ GROWING SEASON}

SUMMARY: The irrigated fruit crop production in the Submédio São Francisco Valley is a major source of income and employment in that region, especially viticulture. In order to determine the availability of potassium in soil solution as function of five rates $\left(0,20,40,80\right.$ and $\left.160 \mathrm{~kg} \mathrm{ha}^{-1}\right)$, an experiment was carried out at Embrapa Tropical Semi-Arid, in Petrolina, State of Pernambuco, Brazil, with grapevine (Vitis vinifera L.) cv. Syrah grafted on rootstock Paulsen 1103 in a 3 x $1 \mathrm{~m}$ spacing. The irrigation system used was drip with one $2 \mathrm{~L}^{-h^{-1}}$ emitter per vine. Soil solution extractors with porous cups were installed at 0.4 and $0.6 \mathrm{~m}$ depths. The concentration of potassium $\left(\mathrm{K}, \mathrm{mg} \mathrm{L}^{-1}\right)$ and nitrate $\left(\mathrm{N}^{-\mathrm{NO}_{3}}, \mathrm{mg} \mathrm{L}^{-1}\right), \mathrm{pH}$ and electrical conductivity $\left(\mathrm{EC}, \mathrm{dS} \mathrm{m}^{-1}\right)$ in the soil solution were evaluated over 111 days. Data were subjected to analysis of variance and linear and polynomial regressions. Means were compared between the studied depths by $\mathrm{F}$ test at $5 \%$ probability. The rates evaluated had a significant effect for the potassium concentration, and presented a linear increase of 0.45 and $0.33 \mathrm{mg} \mathrm{L}^{-1}$ (at 0.4 and $0.6 \mathrm{~m}$ depths, respectively) in the soil solution for each unitary increase $\left(\mathrm{kg} \mathrm{ha}^{-1}\right)$ of potassium fertilizer in the soil. Increasing rates of potassium fertilizer increased the concentration of $\mathrm{K}$ in the soil solution, but it was not observed leaching losses.

KEYWORDS: Vitis vinifera L., fertirrigation, soil solution

\footnotetext{
${ }^{1}$ Pesquisador, Embrapa Semiárido, Caixa Postal 23, CEP 56302-970, Petrolina, PE. Fone (87) 3866.3600. email: davi.jose@embrapa.br;

${ }^{2}$ Doutorando, Depto. de Engenharia Rural, UNESP/FCA, Botucatu, SP.

${ }^{3}$ Acadêmico de Ciências Biológicas, UPE, Petrolina, PE.
}

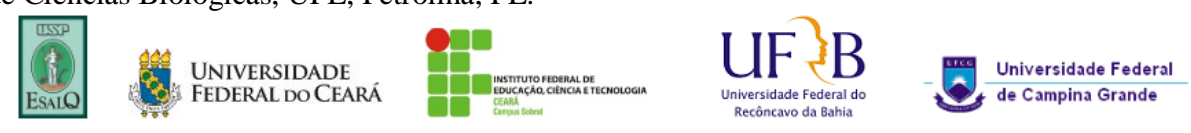




\section{INTRODUÇÃO}

A vitivinicultura é uma atividade de grande importância social e econômica para a região do Submédio São Francisco. Apesar do pequeno número de vinícolas, a região é responsável pela produção anual de 6 milhões de litros de vinho, o que representa $15 \%$ da produção brasileira de vinhos finos de mesa.

A viticultura se expandiu para o Semiárido do Nordeste brasileiro, situado entre os paralelos $8^{\circ}$ $\mathrm{S}$ e $10^{\circ} \mathrm{S}$, com características muito peculiares e exclusivas, correspondendo a uma região única no mundo. Como nesta região ocorre grande variabilidade espacial e temporal de disponibilidade de água no solo, o sucesso da vitivinicultura tropical exigiu o uso de técnicas que pudessem corrigir a deficiência de água no solo (Moura et al., 2009).

A irrigação é essencial para atender a demanda hídrica da videira ao longo do seu ciclo de cultivo. Com a utilização de sistemas de irrigação localizada, como o gotejamento e a microaspersão, foi criada a oportunidade para o emprego da fertirrigação de forma eficiente (Bravdo, 2008). A fertirrigação permite a aplicação uniforme dos nutrientes na região onde está concentrado o maior volume de raízes ativas. Isto aumenta a eficiência de utilização dos fertilizantes comparado a adubação convencional. Por meio do manejo adequado, a fertirrigação proporciona economia de mão de obra, redução dos custos com fertilizantes, diminiu a contaminação da água do solo, possibilita a aplicação dos nutrientes na quantidade adequada e no momento de maior demanda pela planta, além de aumentar a produtividade e a qualidade da produção (Bravdo, 2008; Sharma et al., 2008).

O conhecimento da composição química da solução do solo poderá fornecer subsídios importantes no manejo da fertirrigação. Apesar da importância, existe dificuldades na obtenção da solução do solo. Vários métodos se propõem a fornecer a "verdadeira solução do solo". Contudo, a maior parte desses métodos são morosos e aplicáveis apenas em condiçõs de laboratório como, centrifugação, aplicação de vácuo no extrato saturado e soluções aquosas, deslocamento de solução em coluna e câmara de pressão.

Os extratores de cápsulas porosas constituem um método expedito e que pode ser utilizado diretamente no campo, apresentando ainda como vantagens o manejo fácil, custo relativamente baixo e o fato de o extrato obtido não requerer tratamentos prévios às determinações físico-químicas e à quantificação dos seus componentes. Podem ser citadas como limitações a obstrução dos poros das cápsulas com colóides do solo e a consequente necessidade de aumentar o vácuo e o tempo de coleta da solução. A perda de $\mathrm{CO}_{2}$ e de outros componentes voláteis alteram o pH da solução do solo alterando a sua composição. Além disso, a formação de uma capa coloidal de alta reatividade na superfície externa das cápsulas e a precipitação de óxidos e hidróxidos de ferro na superfície interna durante a extração em ambiente de redução, podem alterar a concentração de $\mathrm{Fe}$ em solução e modificar a concentração de outros elementos, por causa dos processos de sorção e coprecipitação (Moraes \& Dynia, 1990).

Souza et al. (2012) consideram que a análise da solução do solo, obtida por extratores com cápsula de cerâmica porosa, pode ser considerada ferramenta auxiliar para monitorar e avaliar a disponibilidade de nutrientes às plantas. $\mathrm{O}$ extrator de solução ainda é capaz de determinar a mobilidade dos íons no bulbo molhado (Salomão et al., 2012).

O potássio é o nutriente exportado em maior quantidade pela videira (Terra 2003; Albuquerque et al., 2005). É um nutriente importante para a manutenção da quantidade de água nas plantas, uma vez que a absorção de água pela célula e pelos tecidos é, frequentemente, consequência da absorção ativa do potássio (Malavolta, 1996). O mecanismo de abertura e fechamento dos estômatos que promove a saída de $\mathrm{H}_{2} \mathrm{O}$ e a entrada de $\mathrm{CO}_{2}$ depende inteiramente do fluxo desse cátion nas células estomáticas, bem como está envolvido na síntese da enzima ribulose 1,5-bifosfato carboxilase oxigenase e no crescimento meristemático. Fitohormônios que estão envolvidos no crescimento de tecidos meristemáticos são ativados pelo potássio (Taiz \& Zieger, 2009). Este nutriente não promove somente a translocação de fotoassimilados recém-produzidos, mas também tem um efeito benéfico na mobilização de material estocado (Koch \& Mengel, 1977). Por ser um elemento que não forma compostos na planta, permanece livre para regular muitos processos essenciais, incluindo ativação enzimática, fotossíntese, atuando no controle do uso eficiente da água, na síntese de amido e de proteína (Malavolta, 1996). 
Klein et al., (2000) avaliaram a taxa ótima de irrigação por gotejamento para videiras 'Sauvignon blanc', 'Merlot' e 'Cabernet Sauvignon' na região semidesértica do Platô de Arad, Israel. A quantidade de água estimada pelo tanque Classe A foi multiplicada pelos coeficientes 0,3, 0,4 e 0,5, sendo mantido o último coeficiente até o final do ciclo de produção. $\mathrm{O}$ estado nutricional foi avaliado por meio da análise de pecíolo e do limbo foliar em duas épocas, florescimento e colheita. As concentrações de $\mathrm{N}, \mathrm{P}$ e $\mathrm{K}$ foram alteradas pelos volumes de irrigação avaliados, assim como a produção das videiras. $\mathrm{O}$ estado nutricional das videiras com relação ao $\mathrm{N}$ esteve adequado em todas as avaliações. No primeiro ano de avaliação, o teor de $\mathrm{P}$ no limbo (menos de $1,0 \mathrm{~g} \mathrm{~kg}^{-1}$ na colheita) se mostrou deficiente, enquanto os teores de $\mathrm{K}$ no pecíolo aumentaram (20-30 $\mathrm{g} \mathrm{kg}^{-1}$ na colheita), indicando que houve consumo de luxo deste nutriente. O coeficiente 0,3 do tanque Classe A reduziu significativamente a produção dos três cultivares. A taxa mais alta de irrigação-fertirrigação (com coeficiente 0,5) proporcionou um aumento insignificante na produção do cultivar Sauvignon blanc, reduziu do Cabernet Sauvignon e aumentou significativamente do Merlot.

Sierra \& Alfaro (2008) avaliaram a resposta de videiras 'Muscat Rosada' ao P e ao K nas dosagens anuais de $200 \mathrm{~kg} \mathrm{ha}^{-1} \mathrm{e} 300 \mathrm{~kg} \mathrm{ha}^{-1}$, respectivamente. A resposta à adubação com $\mathrm{P}$ foi obtida no segundo ano de avaliação, e ao $\mathrm{K}$ apenas no terceiro ano, com menos de $5 \mathrm{mg} \mathrm{kg}^{-1}$ de $\mathrm{P}$ disponível e menos de $145 \mathrm{mg} \mathrm{kg}^{-1}$ de $\mathrm{K}$ trocável no solo, respectivamente. $\mathrm{O}$ baixo conteúdo inicial proporcionou alta probabilidade de resposta a aplicação de ambos os nutrientes.

Salomão et al. (2012) avaliaram a distribuição de potássio na solução do solo, quando aplicado via fertirrigação pelo sistema de irrigação por gotejamento em um pomar de citrus cultivado em solo arenoso, visando definir o adequado posicionamento dos extratores de solução. Eles verificaram que as maiores concentrações de potássio foram observadas na faixa de $5 \mathrm{~cm}$ a $25 \mathrm{~cm}$ de distância do emissor na horizontal e entre 15 e $0,6 \mathrm{~m}$ de profundidade. A distribuição do íon ao longo do perfil foi homogênea, mostrando que o fluxo de $\mathrm{K}$ foi afetado pelo movimento da água no solo, pois a distribuição da umidade também foi bastante homogênea. Considerando como ponto de referência a maior concentração de potássio no bulbo molhado $\left(115 \mathrm{mg} \mathrm{L}^{-1}\right)$, os autores recomendam a instalação dos extratores de solução na faixa de $0,15 \mathrm{~m}$ de distância do emissor e a $0,30 \mathrm{~m}$ de profundidade.

Com a expansão da área cultivada com videira irrigada no Vale do São Francisco, a técnica de fertirrigação foi adotada de maneira a reduzir custos e aumentar a produtividade da cultura. Porém, observa-se ainda nos dias atuais a necessidade de estudos sobre a quantidade adequada de fertilizantes a serem aplicadas no cultivo da videira de vinho, a dinâmica dos nutrientes no solo, como o potássio, pois além das questões de produção, que são de extrema importância, a quantidade de nutrientes disponíveis na solução solo pode influênciar de maneira significativa na qualidade das uvas e dos vinhos produzidos.

Por este motivo, a utilização de extratores de cápsulas porosas pode ser uma ferramenta útil para o monitoramento da concentração dos nutrientes no solo de maneira eficaz e rápida, podendo-se corrigir a adubação caso seja necessário (Silva et al., 2000).

O objetivo deste trabalho foi avaliar a dinâmica de potássio na solução do solo após a aplicação deste nutriente via fertirrigação em diferentes dosagens, assim como o seu comportamento nas diferentes profundidades do solo nas quais se localiza o sistema radicular efetivo da videira.

\section{MATERIAL E MÉTODOS}

O experimento foi instalado no Campo Experimental de Bebedouro (latitude $9^{\circ} 8,8,9^{\prime} \mathrm{S}$, longitude $40^{\circ} 18^{\prime} 33,6^{\prime \prime}$ O, altitude $373 \mathrm{~m}$ ) pertencente a Embrapa Semiárido em Petrolina-PE. A videira (Vitis vinifera L.) cultivar Syrah foi enxertada sobre o porta enxerto Paulsen 1103. O plantio no campo foi realizado em 30 de abril de 2009, no espaçamento de $1 \mathrm{~m}$ entre plantas e $3 \mathrm{~m}$ entre fileiras e a condução feita no sistema de espaldeira. O solo da área foi classificado como Argissolo Vermelho Amarelo Eutrófico Latossólico, textura média (Silva, 2005), apresentando, na camada de 0 a $0,2 \mathrm{~m}$ de profundidade: areia $81 \mathrm{~g} \mathrm{~kg}^{-1}$, silte $13 \mathrm{~g} \mathrm{~kg}^{-1}$ e argila $6 \mathrm{~g} \mathrm{~kg}^{-1}$; matéria orgânica $10,4 \mathrm{~g} \mathrm{~kg}^{-1} ; \mathrm{pH}$ em água 6,7; CE 0,46 dS m $\mathrm{d}^{-1}$; $\mathrm{P}$ disponível 88,8 $\mathrm{mg} \mathrm{dm}^{-3}$; $\mathrm{K}$ disponível 3,8 mmolc dm $\mathrm{dm}^{-3}$; Ca trocável 25,4 mmolc $\mathrm{dm}^{-3} ; \mathrm{Mg}$ trocável 9,8 mmolc $\mathrm{dm}^{-3}$; Na trocável 0,3 mmolc $\mathrm{dm}^{-3}$; Al trocável 0,5 mmolc $\mathrm{dm}^{-3}$;

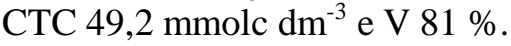


Os tratamentos foram constituídos de cinco doses de potássio $\left(0,20,40,80\right.$ e $\left.160 \mathrm{~kg} \mathrm{ha}^{-1}\right)$ dispostos em blocos casualizados com cinco repetições. A unidade experimental foi constituída de 16 plantas, sendo oito plantas úteis.

A irrigação foi realizada em sistema de gotejamento, com emissores espaçados em $0,5 \mathrm{~m}$ na linha, com vazão de $2 \mathrm{~L} \mathrm{~h}^{-1}$. Para a fertirrigação foram utilizados os seguintes fertilizantes: sulfato de potássio $\left(\mathrm{K}_{2} \mathrm{O}=50 \%\right.$ e $\left.\mathrm{S}=17 \%\right)$, cloreto de potássio branco $\left(\mathrm{K}_{2} \mathrm{O}=60 \%\right.$ e $\left.\mathrm{Cl}=48 \%\right)$ e nitrato de potássio $\left(\mathrm{K}_{2} \mathrm{O}=45 \%\right.$ e $\left.\mathrm{N}=12 \%\right)$. A aplicação foi realizada por meio de bomba injetora elétrica. $\mathrm{O}$ manejo da irrigação foi conduzido através da evapotranspiração da cultura (ETc). Os fertilizantes foram aplicados em regime de fertirrigação periódica em 10 semanas, sendo $40 \%$ nas primeiras quatro semanas e $60 \%$ nas semanas seguintes. A poda de produção foi realizada no dia 29 de abril de 2013 , iniciando os eventos de fertirrigação 14 dias após a poda de produção (dapp).

Para extração da solução do solo, foram instalados 30 extratores de cápsulas porosas na área experimental nas profundidades de 0,4 e 0,6 m, distanciados em $0,1 \mathrm{~m}$ dos emissores e a $0,3 \mathrm{~m}$ da planta. O extrator de solução do solo foi composto de tubo de PVC, conectado na extremidade inferior a uma cápsula de cerâmica porosa. Na extremidade superior o extrator foi vedado com rolha, e por esta passavam dois tubos de naylon, em um deles se aplicava o vácuo e no outro ficava conectado uma seringa por onde se coletava a solução. Após cada evento de fertirrigação, com o auxílio de uma bomba de vácuo manual os extratores eram submetidos a uma aplicação de vácuo com tensão de 60 $\mathrm{kPa}$. Um dia após esta aplicação, as soluções do solo eram coletadas e levadas para o Laboratório de Análise de Solos e Plantas da Embrapa Semiárido onde foram determinadas as concentrações de potássio $\left(\mathrm{K} \mathrm{mg} \mathrm{L}^{-1}\right)$, nitrato $\left(\mathrm{N}-\mathrm{NO}_{3}, \mathrm{mg} \mathrm{L}^{-1}\right)$, $\mathrm{pH}$ e condutividade elétrica $\left(\mathrm{CE}, \mathrm{dS} \mathrm{m}^{-1}\right)$ conforme Silva et al. (2000). Foram realizadas 11 coletas de solução do solo ao longo do experimento (uma coleta por semana).

No momento da realização da coleta da solução, foi verificada a umidade do solo por meio de tensiômetros de punção. Foram instaladas duas baterias de tensiômetros nas mesmas posições que foram instalados os extratores de solução.

Os dados foram submetidos à análise de variância e de regressão linear e polinomial. As médias foram comparadas entre as profundidades estudadas $(0,4 \mathrm{a} 0,6 \mathrm{~m})$ pelo teste $\mathrm{F}$ a $5 \%$ de probabilidade. A análise estatística foi realizada com o programa Sisvar (Ferreira, 2008).

\section{RESULTADOS E DISCUSSÃO}

Na Figura 1 são mostradas as concentrações de potássio na solução do solo nas diferentes dosagens estudadas. A $0,4 \mathrm{~m}$ de profundidade (A) praticamente não ocorre aumento da concentração de K na solução do solo, em relação ao tratamento testemunha para as menores dosagens de K, de 20 e $40 \mathrm{~kg} \mathrm{ha}^{-1}$ de $\mathrm{K}_{2} \mathrm{O}$, com ligueiro decréscimo nas concentração de $\mathrm{K}$ ao longo do ciclo de produção da videira para estes tratamentos. Em um estudo realizado durante 15 semanas, Moraes \& Dynia (1990) observaram que, a $20 \mathrm{~cm}$ de profundidade, as concentrações de $\mathrm{Ca}, \mathrm{Mg}, \mathrm{K}$ e $\mathrm{N}^{-\mathrm{NO}_{3}}$ diminuíram rapidamente a partir da quarta semana, atingindo valores muito baixos. Simultaneamente aumentaram as concentrações desses nutrientes nas profundidades de 0,4 e $0,6 \mathrm{~m}$, o que demonstra a sua lixiviação. Por outro lado, Souza et al., (2012), não observaram perdas de nutrientes por lixiviação na solução do solo na média das variáveis analisadas (amônio, nitrato, $\mathrm{P}$ e K) durante 11 meses de amostragem, em ensaios realizados em pomares de laranjeira.

Observa-se um aumento progressivo da concentração de $\mathrm{K}$ dos 44 aos 73 dias após a poda (dapp) na profundidade $0,4 \mathrm{~m}$ (A) para as dosagens 80 e $160 \mathrm{~kg} \mathrm{ha}^{-1}$ de $\mathrm{K}_{2} \mathrm{O}$ e de 33 a 63 dapp na profundidade 0,6 m (B) para todas as dosagens de $\mathrm{K}_{2} \mathrm{O}$, com exceção de testemunha. Entretanto, nesta mesma profundidade, a concentração de K na solução é reduzida a partir de 97 dapp em todos os tratamentos. Segundo Terra (2003) a necessidade de K na videira é mais intensa nos estádios de lignificação dos ramos e maturação dos frutos. Considerando as funções fisiológicas do potássio, processos como a transpiração são intensificados nesta fase de desenvolvimento da planta, que requer um controle mais eficiente do uso da água, por meio da abertura e fechameno dos estômatos (Taiz \& Zieger, 2009).

Com relação ao movimento do potássio no perfil do solo, Salomão et al. (2012) observaram que as maiores concentrações de potássio foram obtidas na faixa de 0,05 a $0,25 \mathrm{~m}$ de distância do emissor na horizontal e entre 0,15 e $0,6 \mathrm{~m}$ de profundidade, mostrando distribuição homogênea ao longo do 
perfil e indicando que o fluxo de $\mathrm{K}$ foi afetado pelo movimento da água no solo, pois a distribuição da umidade também foi bastante homogênea. Considerando como ponto de referência a maior concentração de potássio no bulbo molhado $\left(115 \mathrm{mg} \mathrm{L}^{-1}\right)$, os autores recomendam a instalação dos extratores de solução na faixa de $15 \mathrm{~cm}$ de distância do emissor e a $0,3 \mathrm{~m}$ de profundidade para avaliação da disponibilidade de potássio na solução do solo em pomares de laranjeira.

A condutividade elétrica (CE) na solução do solo durante o ciclo de cultivo da videira é mostrada na Figura 2. Observa-se que os tratamentos que receberam as maiores dosagens ( $80 \mathrm{e} 160 \mathrm{~kg}$ $\mathrm{ha}^{-1}$ de $\mathrm{K}_{2} \mathrm{O}$ ) apresentaram maiores valores de $\mathrm{CE}$ na profundidade $0,4 \mathrm{~m}$, havendo redução dos valores de CE para todos os tratamentos a partir de 97 dapp, seguindo a mesma tendência das concentrações de potássio. Por outro lado, houve uma aproximação nos valores de CE na profundidade 0,6 m, sendo observados os maiores valores aos 91 dapp. No período de 97 a 111 dapp os valores foram reduzidos, assim como as concentrações de $\mathrm{K}$ e outros nutrientes na solução do solo. Em pomares com laranjeira, Souza et al. (2012) obtiveram aumento dos valores de condutividade elétrica da solução do solo conforme o aumento da dose aplicada de fertilizantes. Esse aumento ocorreu de modo similar a 0,3 e 0,6 m de profundidade. Segundo Silva (2012) o monitoramento da CE na solução do solo com o uso de extratores de cápsulas porosas pode auxiliar no manejo da fertirrigação, evitando o risco de salinidade das plantas devido a alta dosagens de nutrientes. Isto pode ser aplicado às regiões semiáridas, pois irrigações elevadas e aplicações excessivas de fertilizantes podem contribuir para o aumento da salinidade do solo.

A análise de regressão revela que houve aumento linear dos valores de $\mathrm{CE}, \mathrm{K}$ e $\mathrm{N}_{-} \mathrm{NO}_{3}$ na solução do solo em resposta às doses crescentes de potássio a $0,4 \mathrm{~m}$ de profundidade (Tabela 1 ). Na profundidade $0,6 \mathrm{~m}$ apenas as concentrações de $\mathrm{K}$ apresentaram aumento linear. Houve acréscimo de 0,45 e $0,33 \mathrm{mg} \mathrm{L}^{-1}$ na concentração de $\mathrm{K}$ na solução do solo, nas profundidades 0,4 e $0,6 \mathrm{~m}$, respectivamente, para cada aumento unitário de $\mathrm{K}_{2} \mathrm{O}\left(\mathrm{kg} \mathrm{ha}^{-1}\right)$ no solo, enquanto a variável condutividade elétrica apresentou acréscimo de $0,006 \mathrm{dS} \mathrm{m}^{-1}$ para cada aumento unitário de de $\mathrm{K}_{2} \mathrm{O}$ $\left(\mathrm{kg} \mathrm{ha}^{-1}\right)$ no solo a 0,4 $\mathrm{m}$ de profundidade. Souza et al. (2012) também observaram que os teores de amônio, nitrato, $\mathrm{P}$ e $\mathrm{K}$ na solução do solo aumentaram com o aumento das doses aplicadas de fertilizantes, tanto a 0,3 quanto a 0,6 m de profundidade. Segundo Fregoni (1980), o potássio exerce importante papel na formação de carboidratos das folhas e consequentemente no teor de açúcares totais da uva.

A comparação entre as duas profundidades avaliadas, realizada por meio do teste $\mathrm{F}$ (Tabela 1) não apresentou diferenças significatvas para nenhuma das variáveis analisadas, o que demonstra um manejo eficiente da irrigação, pois os nutrientes conseguiram alcançar a profundidade efetiva da raiz ao longo do perfil do solo (Bassoi et al., 2003). Não houve efeito significativo para a interação entre doses de potássio e profundidades para nenhuma das variávies analisadas.

\section{CONCLUSÕES}

Dosagens crescentes de fertilizantes potássicos aumentaram a concentração de potássio na solução do solo, não sendo observadas perdas por lixiviação deste nutriente. As dosagens utilizadas não apresentaram efeito sobre o pH da solução do solo, nem aumento significativo da CE na solução do solo, capaz de provocar estresse salino na videira.

\section{AGRADECIMENTOS}

Os autores agradecem à Coordenação de Aperfeiçoamento de Pessoal de Nível Superior (CAPES) pela concessão da bolsa de estudo e ao CNPq pela bolsa de iniciação científica e de produtividade aos autores. À Embrapa Semiárido pela estrutura disponibilizada durante o experimento.

\section{REFERÊNCIAS BIBLIOGRÁFICAS}

AlBUQUERQUE, T. C. S. de; AlBUQUERQUE NETO, A. A. R. de; DEON, M. D. Exportação de nutrientes pelas videiras cvs. Itália e Benitaka cultivadas no Vale do São Francisco. In: CONGRESSO BRASILEIRO DE FISIOLOGIA VEGETAL, 10.; CONGRESSO LATINO 
AMERICANO DE FISIOLOGIA VEGETAL, 12., 2005, Recife. Anais... Recife: SBFV, 2005. CDROM.

BASSOI, L. H.; HOPMANS, J. W.; JORGE, L. A. C.; ALENCAR, C. M.; SILVA, J. A. M. Grapevine root distribution in drip and microsprinkler irrigation. Scientia Agricola, v.60, n.2, p.377-387, 2003. http://dx.doi.org/10.1590/S0103-90162003000200024

BRAVDO, B. Nutrient management in table and wine grapes by fertigation. Acta Horticulture, v. 785, p. $165-174,2008$.

FERREIRA, D.F. SISVAR: um programa para análises e ensino de estatística. Revista Symposium, v.6, p.36-41, 2008.

FREGONI, M. Nutrizione e fertilizzazione della vite. Bologna: Edagricole, 1980. 418p.

KLEIN, I; STRIME, M; FANBERSTEIN, L.; MANI, Y. Irrigation and fertirrigation effects on phosphorus and potassium nutrition of wine grapes. Vitis, v. 39, n. 2, p.55-62, 2000.

$\mathrm{KOCH}, \mathrm{K}$; MENGEL, K. Effect of $\mathrm{K}$ on $\mathrm{N}$ utilization by spring wheat during grain formation $\begin{array}{lllll}\text { Agronomy } & \text { Journal. } & \text { v. } & 69, & \text { p.477-480, }\end{array}$ http://dx.doi.org/10.2134/agronj1977.00021962006900030036x

MALAVOLTA, E. Potássio é uma realidade. O potássio é essencial para todas as plantas. Potafos. Piracicaba, 1996. Arquivo do Agrônomo, n.10.

MORAES, J.F.V.; DYNIA, J.F. Uso de cápsulas porosas para extrair solução do solo. Pesquisa Agropecuária Brasileira, v.25, p.1523-1528, 1990.

MOURA, M.S.B; TEIXEIRA, A.H.C.; SOARES, J.M. Exigências climáticas. In: SOARES, J.M.; LEÃO, P.C.S. (Eds.) A vitivinicultura no semiárido brasileiro. Brasília, DF: Embrapa Informação Tecnológica; Petrolina: Embrapa Semiárido, 2009. p. 35-69.

SALOMÃO, L.C.; SOUZA, T.R.; VILLAS BÔAS, R.L.; ANDRADE, T.F.; FORATTO, L.C.; O J. M. SANTOS, A.J.M. Posicionamento de extratores de cápsula porosa em solo arenoso na citricultura fertirrigada por gotejamento. Irriga, Botucatu, v. 17, p. 469-480, 2012.

SHARMA, J.; UPADHYAY, A.K.; SHIKHAMANY, S.D.; SINGH, R.K. Effect of fertilizer application through irrigation water on Thompson Seedless grape yield and fertilizer use efficiency. Acta Horticulturae, v. 785, p.399-408, 2008.

SIERRA B., C.; ALFARO P., R. Potassium and phosphorus in Muscat Rosada grape yield in Elqui Valley soil. Chilean Journal of Agricultural Research, v. 68, n.3, p.297-303, 2008. http://dx.doi.org/10.4067/S0718-58392008000300010

SILVA, A.O. Fertirrigação e controle da salinidade em cultivo de beterraba em ambiente protegido. Botucatu, 2012. 157p. Dissertação (Mestrado em Agronomia) - Faculdade de Ciências Agronômicas, UNESP.

SILVA, J. A. M. Irrigação lateralmente alternada e com deficit hídrico na videira cv. Petite Syrah. 2005. 99 f. (Dissertação, Universidade Federal de Viçosa).

SILVA, E. F. F. ANTI, G. R.; CARMELLO, Q. A. C.; DUARTE, S. N. Extratores de capsulas porosas para o monitoramento da condutividade elétrica e do teor de potássio na solução do solo. Scientia Agrícola, Piracicaba, v. 57, n. 4, p. 785-789, 2000.

SOUZA, T.R.; VILLAS BÔAS, R.L.; QUAGGIO, J.A.; SALOMÃO, L.C.; FORATTO, L.C. Dinâmica de nutrientes na solução do solo em pomar fertirrigado de citros. Pesquisa Agropecuária Brasileira, Brasília, v.47, n.6, p.846-854, 2012. http://dx.doi.org/10.1590/S0100204X2012000600016

TAIZ, L.; ZEIGER, E. Fisiologia vegetal. 4.ed. Porto Alegre: Artmed, 2009. 819p.

TERRA, M. M. Nutrição, calagem e adubação. In: POMMER, C. V. (Ed.). Uva: tecnologia de produção, pós-colheita, mercado. Porto Alegre: Cinco Continentes, 2003. p. 405-476. 

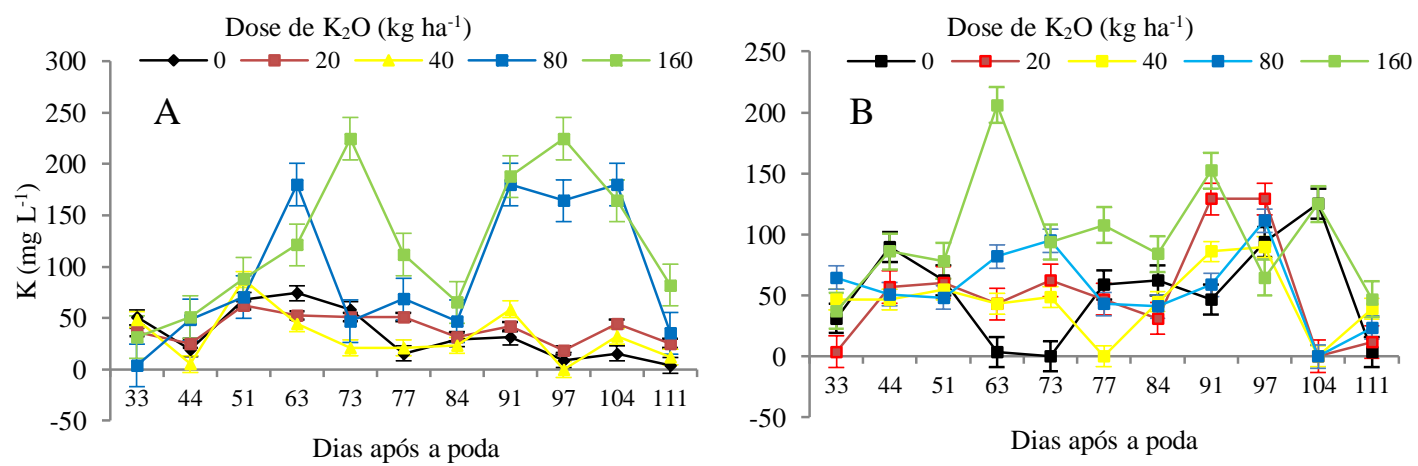

Figura 1. Distribuição de potássio na solução do solo ao longo do ciclo de cultivo da videira nas profundidades $0,4(\mathrm{~A})$ e $0,6 \mathrm{~m}(\mathrm{~B})$.
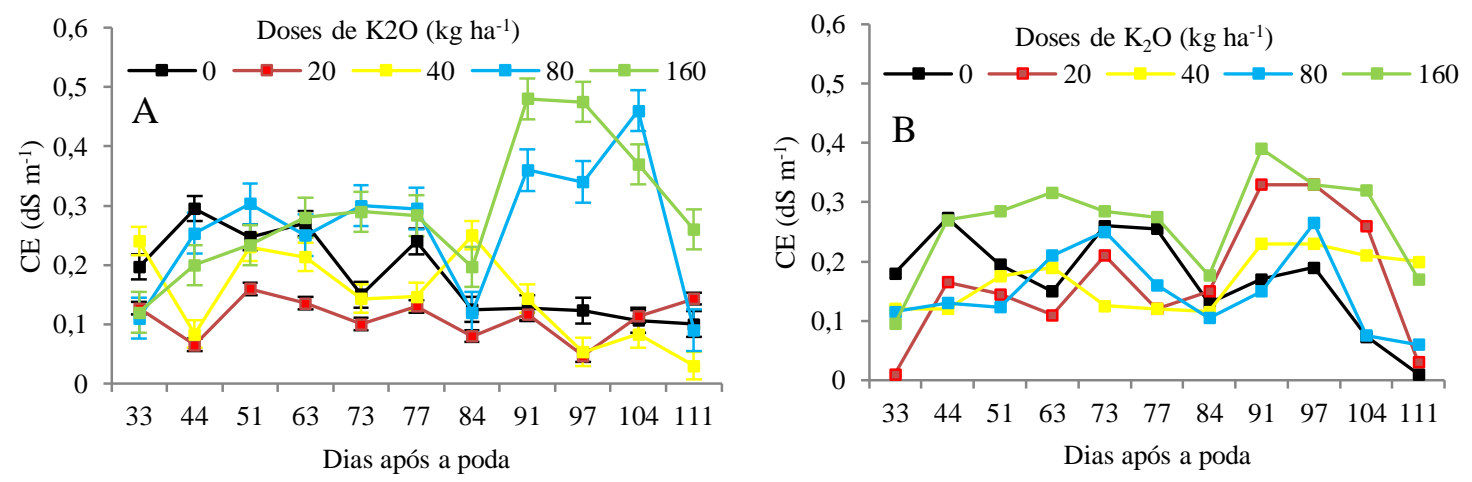

Figura 2. Distribuição da condutividade elétrica na solução do solo ao longo do ciclo de cultivo da videira nas profundidades 0,4 (A) e $0,6 \mathrm{~m}$ (B). 
Tabela 1. Resultados da análise de regressão e do teste $\mathrm{F}$ das variáveis $\mathrm{pH}, \mathrm{CE}$ e concentrações de $\mathrm{K}$ e $\mathrm{N}-\mathrm{NO}_{3}$ na solução do solo (média de 11 coletas semanais) em duas profundidades, em função de doses de potássio aplicadas via fertirrigação em videiras

\begin{tabular}{|c|c|c|c|c|}
\hline Tratamento $^{(1)}$ & $\mathrm{pH}$ & $\mathrm{CE}$ & $\mathrm{K}$ & $\mathrm{N}-\mathrm{NO}_{3}$ \\
\hline & & $\mathrm{dS} \mathrm{m}^{-1}$ & ----------- & - \\
\hline \multirow{2}{*}{\multicolumn{5}{|c|}{ Profundidade $0,4 \mathrm{~m}$}} \\
\hline & & & & \\
\hline 0 & 7,91 & 0,13 & 25,71 & 17,74 \\
\hline 20 & 7,75 & 0,08 & 28,44 & 21,74 \\
\hline 40 & 7,93 & 0,13 & 29,98 & 18,29 \\
\hline 80 & 8,00 & 0,15 & 47,16 & 24,02 \\
\hline 160 & 7,83 & 0,22 & 95,26 & 30,05 \\
\hline Tratamento & $3,40^{\mathrm{ns}}$ & $85,73 *$ & $2561,17 * *$ & $75,15^{\mathrm{ns}}$ \\
\hline Regressão & $\mathrm{L}^{\mathrm{ns}}$ & $\mathrm{L}^{*}$ & $\mathrm{~L}^{* *}$ & $\mathrm{~L}^{*}$ \\
\hline \multirow[t]{2}{*}{$\mathrm{R}^{2}$} & 0,55 & 0,49 & 0,73 & 0,39 \\
\hline & \multicolumn{4}{|c|}{ Profundidade $0,6 \mathrm{~m}$} \\
\hline \multicolumn{2}{|l|}{$\mathrm{kg} \mathrm{ha}^{-1}$ de $\mathrm{K}_{2} \mathrm{O}$} & \multicolumn{2}{|c|}{$\mathrm{dS} \mathrm{m}^{-1}$} & ----- \\
\hline 0 & 7,91 & 0,10 & 24,05 & 21,88 \\
\hline 20 & 7,78 & 0,08 & 24,29 & 18,58 \\
\hline 40 & 7,77 & 0,08 & 20,85 & 13,45 \\
\hline 80 & 7,79 & 0,10 & 37,80 & 16,83 \\
\hline 160 & 7,86 & 0,19 & 74,41 & 22,44 \\
\hline Tratamento & $1,16^{\mathrm{ns}}$ & $61,56^{\mathrm{ns}}$ & $1482,74 *$ & $41,40^{\mathrm{ns}}$ \\
\hline Regressão & $\mathrm{Q}^{\mathrm{ns}}$ & $\mathrm{L}^{\mathrm{ns}}$ & $\mathrm{L}^{*}$ & $\mathrm{Q}^{\mathrm{ns}}$ \\
\hline \multirow[t]{2}{*}{$\mathrm{R}^{2}$} & 0,68 & 0,37 & 0,59 & 0,22 \\
\hline & \multicolumn{3}{|c|}{ Teste $\mathrm{F}^{(2)}$} & \\
\hline \multicolumn{5}{|c|}{ Profundidade (m) } \\
\hline 0,4 & $7,8 \mathrm{a}$ & $0,14 \mathrm{a}$ & $45,33 \mathrm{a}$ & $22,37 \mathrm{a}$ \\
\hline 0,6 & $7,3 \mathrm{a}$ & $0,11 \mathrm{a}$ & $36,23 \mathrm{a}$ & $18,63 \mathrm{a}$ \\
\hline
\end{tabular}

(1) Dose de potássio aplicada em cada tratamento; $* *$ e $*$ significativo a $1 \%$ e $5 \%$ de probabilidade; ${ }^{\text {ns: }}$ não significativo; $\mathrm{L}=$ linear e $\mathrm{Q}=$ quadrática. $^{(2)}$ Médias seguidas de letras iguais nas colunas não diferem entre si pelo teste $\mathrm{F}$ a $5 \%$ de probabilidade. 